\title{
Heartbeat: Causes and consequences of atrial fibrillation
}

The prevalence of atrial fibrillation (AF) is increasing dramatically as our population ages ${ }^{1} \mathrm{~A}$ better understanding of risk factors associated with AF is needed to allow earlier detection, or even prevention, of this common arrhythmia which, hopefully, will reduce the population incidence of stroke. ${ }^{2}$ In this issue of Heart, Tikhonoff and colleagues ${ }^{2}$ hypothesised that ambulatory blood pressure (BP) 'may represent a potentially modifiable risk factor for the development of AF in a European population study'. Based on data from almost 4000 subjects (mean age $43.1 \pm 15.1$ years, $52 \%$ women) with a median follow-up of 14 years, they found only a borderline association of conventional systolic BP measurements with incident AF. However, 24 hours ambulatory BP measurements were strongly associated with the risk for incident AF (figure 1). Patients in the upper quartile of daytime systolic BP load (38\% or more of BP readings were over $135 \mathrm{~mm} \mathrm{Hg}$ ) had a $46 \%$ higher risk of incident AF compared with the average population risk.

In the accompanying editorial, Dr Wachtell ${ }^{3}$ points out that 'although the phenotype presentation of atrial fibrillation may have many causes, the most common aetiology is pressure overload as hypertension and the consequent cardiac changes in left atrial and ventricular structure and function'. He goes on to conclude 'that atrial fibrillation should, in fact, be considered as target organ damage even when blood pressure is in the normal range. Thus, when blood pressures are in the normal or high normal range, occurrence of atrial fibrillation should be considered as impaired haemodynamics with increased blood pressure load and central blood pressures. Preventing and treating atrial fibrillation should include reducing cardiovascular risk factors such as reducing blood pressure, improving central haemodynamics and improving the left atrial and ventricular structure and function'.

Coexisting heart failure (HF) is common in patients with AF but often is underdiagnosed because symptoms are attributed to AF. In a meta-analysis of data from four

Correspondence to Professor Catherine M Otto, Division of Cardiology, University of Washington, Seattle,WA 98195, USA; cmotto@uw.edu
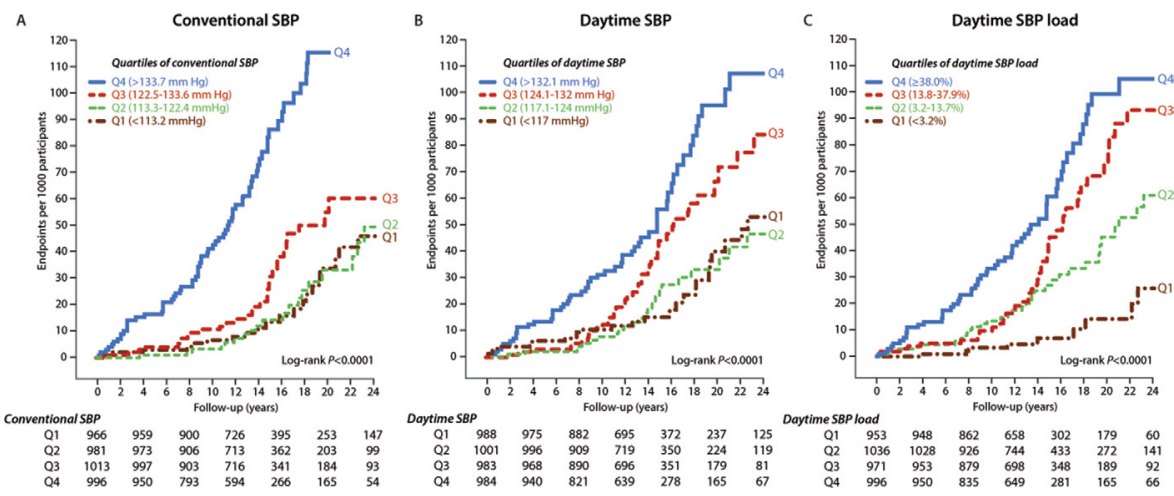

Figure 1 Cumulative incidence estimates (1-Kaplan-Meier survival estimates) for atrial fibrillation events by quartiles of conventional systolic blood pressure (SBP) (A), daytime systolic blood pressure (B) and daytime systolic blood pressure load (C). P values are for the differences between groups according to the log-rank test.

studies including 1941 community-based older adults at high risk of HF, van Doorn and colleagues ${ }^{4}$ found that HF was present in $43 \%$ of patients with $\mathrm{AF}$, compared with $20 \%$ of those without AF at baseline. HF diagnosis was based on echocardiographic evidence of structural or functional abnormalities at rest in patients with symptoms or signs of HF. Using this definition as the reference standard, elevated serum natriuretic peptide levels in the overall population had a sensitivity of $78 \%$ and specificity of $62 \%$ for diagnosis of $\mathrm{HF}$. However, when AF was present, while sensitivity was even higher (93\%) specificity was very low (35\%) for diagnosis of HF (figure 2).

Bettencourt and Lourenço ${ }^{5}$ remind us that 'there is now robust and extensive evidence that natriuretic peptides can

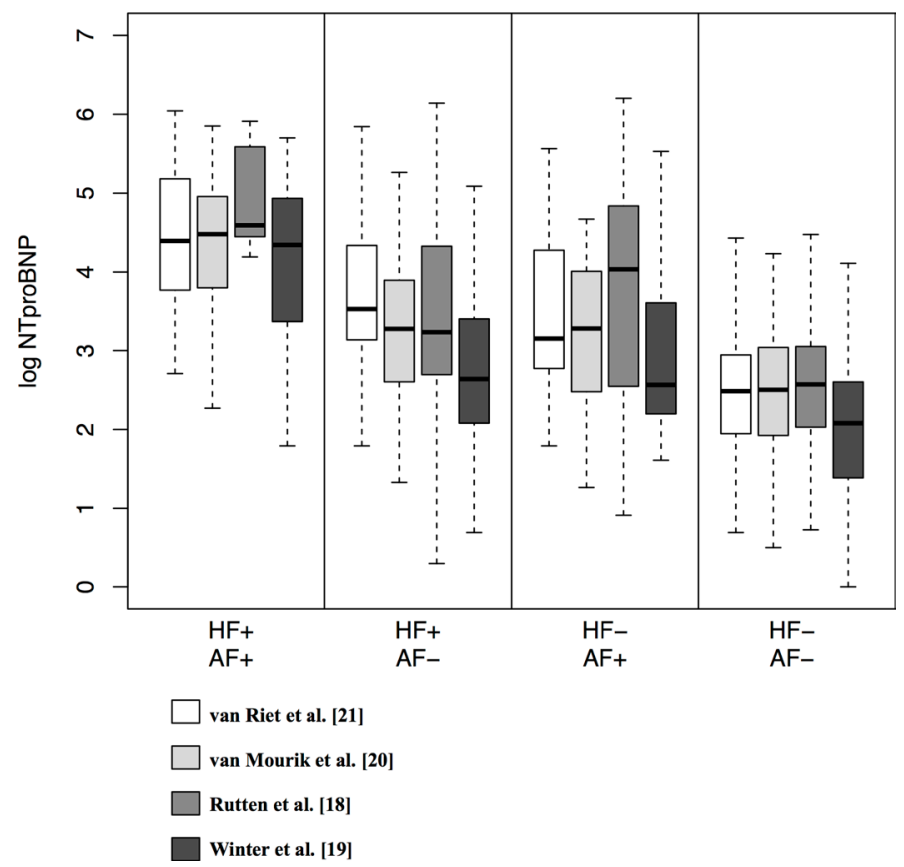

Figure 2 Amino-terminal pro B-type natriuretic peptide (NTproBNP) in patients with/without heart failure (HF) and atrial fibrillation (AF) across studies. Rutten et al. BMJ 2005: 331:1379; Winter et al. Diabetologia 2012: 55: 2154-62; van Mourik et al. BMC Public Health 2012: 12: 385; van Riet et al. BMC Cardiovasc Disord 2014; $12: 1$. 
help clinicians in the diagnosis of acute HF. Even when physicians are uncertain on the mechanism of acute dyspnoea (pulmonary vs cardiac), the knowledge of natriuretic peptide levels gives crucial information. In ambulatory patients, the evidence is not so strong'. In the context of the study by von Doorn et al, it is clear that 'patients with AF are heterogeneous and share common clinical features with patients with HF. Both HFpEF [HF with preserved ejection fraction] and AF are associated with older age, hypertension and diastolic dysfunction; therefore, these conditions are intimately linked. Not all studies have been able to differentiate whether HFpEF or AF comes first, and there are clear diagnostic challenges in clinical practice'.

From a worldwide perspective, there are many barriers to ideal cardiovascular health, particularly in low resource setting. The American Heart Association defines ICH by three clinical metrics (BP, untreated total cholesterol and glucose) and four health behaviours (smoking, body mass index, physical activity and diet) (table 1). In a cohort of over 3000 Peruvian adults, Benziger and colleagues ${ }^{6}$ found that 'no one had all seven ideal metrics; only $41(1.3 \%)$ had 6 ideal health health metric. Females, aged 35-44 years, those living in rural Puno, and those in the lowest socioeconomic tertile had the highest percentage of ideal cardiovascular health' (figure 3).

In an editorial, Brant and Ribeiro ${ }^{7}$ emphasise that improving cardiovascular health $(\mathrm{CVH})$ in low-income and middle-income countries requires that we 'address the first step of the chain, which is to promote ideal CVH. If we want to pursue $\mathrm{CVH}$, we need to keep the populations free from cardiovascular risk factors and thus invest in primordial metrics and $322(10.5 \%)$ had $\leq 1$ ideal

\begin{tabular}{|c|c|c|}
\hline CVH metric & Category & Definition \\
\hline \multirow[t]{3}{*}{ Diet } & Ideal & $4-5$ components* \\
\hline & Intermediate & $2-3$ components* \\
\hline & Poor & 0-1 component* \\
\hline \multirow[t]{3}{*}{ Physical activity } & Ideal & $\begin{array}{l}\geq 150 \mathrm{~min} / \text { week moderate intensity or } \geq 75 \mathrm{~min} / \text { week vigorous intensity or } \\
\text { combination }\end{array}$ \\
\hline & Intermediate & $\begin{array}{l}1-149 \mathrm{~min} / \text { week moderate intensity or } 1-74 \mathrm{~min} / \text { week vigorous intensity or } \\
1-149 \mathrm{~min} / \text { week moderate/vigorous }\end{array}$ \\
\hline & Poor & None \\
\hline \multirow[t]{3}{*}{ Body mass index } & Ideal & $<25 \mathrm{~kg} / \mathrm{m}^{2}$ \\
\hline & Intermediate & $25-29.9 \mathrm{~kg} / \mathrm{m}^{2}$ \\
\hline & Poor & $\geq 30 \mathrm{~kg} / \mathrm{m}^{2}$ \\
\hline \multirow[t]{3}{*}{ Smoking } & Ideal & Never or previous smoker+quit $>12$ months ago \\
\hline & Intermediate & Previous smoker+quit $\leq 12$ months ago \\
\hline & Poor & Current smoker \\
\hline \multirow[t]{3}{*}{ Blood pressure } & Ideal & $<120 / 80 \mathrm{~mm} \mathrm{Hg}$ \\
\hline & Intermediate & SBP $120-139$ or DBP $80-89 \mathrm{~mm} \mathrm{Hg}$ or treated to goal \\
\hline & Poor & $\mathrm{SBP} \geq 140$ or $\mathrm{DBP} \geq 90 \mathrm{~mm} \mathrm{Hg}$ \\
\hline \multirow{3}{*}{$\begin{array}{l}\text { Fasting plasma } \\
\text { glucose }\end{array}$} & Ideal & $<100 \mathrm{mg} / \mathrm{dL}$ \\
\hline & Intermediate & $100-125 \mathrm{mg} / \mathrm{dL}$ or treated to goal \\
\hline & Poor & $\geq 126 \mathrm{mg} / \mathrm{dL}$ \\
\hline \multirow[t]{3}{*}{ Total cholesterol } & Ideal & $<200 \mathrm{mg} / \mathrm{dL}$ \\
\hline & Intermediate & $200-239 \mathrm{mg} / \mathrm{dL}$ or treated to goal \\
\hline & Poor & $\geq 240 \mathrm{mg} / \mathrm{dL}$ \\
\hline
\end{tabular}

${ }^{*}$ Components: (1) fruits and vegetables: $\geq 4.5$ cups per day, (2) fish: $\geq$ two 3.5 oz servings per week (preferably oily fish), (3) fibre-rich whole grains ( $\geq 1.1 \mathrm{~g}$ of fibre per $10 \mathrm{~g}$ of carbohydrate): $\geq$ three $1 \mathrm{oz}$-equivalent servings per day, (4) sodium: $<1500 \mathrm{mg}$ per day and (5) sugar-sweetened beverages: $\leq 450 \mathrm{kcal}$ (36 oz) per week.

CVH, cardiovascular health; DBP, diastolic blood pressure; SBP, systolic blood pressure.

prevention. The challenge of primordial prevention is that it implies a solid integration of diverse areas-such as health professionals, educators and policy makers-to develop and implement strategies that will help counteract the unhealthy habits brought by modernisation'. Perhaps we need to consider whether this vision for promoting global health is relevant to high-income countries as well.

The Education in Heart article ${ }^{8}$ in this issue provides algorithms to select which patients with HF should receive cardiac

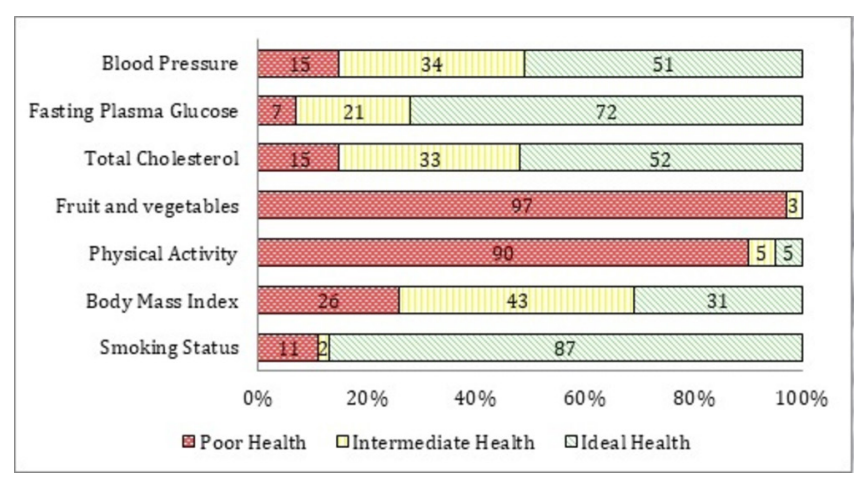

Figure 3 Prevalence estimates for poor, intermediate and ideal cardiovascular health for each of the seven American Heart Association Cardiovascular Health metrics in adults aged $\geq 35$ years $(n=3058)$. resynchronisation therapy (eg, biventricular pacing) and why some patients fail to show improvement with this approach.

The Image Challenge 9 question shows some interesting images in a patient with an incidental murmur; perhaps the stethoscope is still useful sometimes after all!

Competing interests None declared.

Patient consent Not required.

Provenance and peer review Commissioned; internally peer reviewed.

(c) Article author(s) (or their employer(s) unless otherwise stated in the text of the article) 2018. All rights reserved. No commercial use is permitted unless otherwise expressly granted.

\section{Check for updates}

To cite Otto CM. Heart 2018;104:1229-1231.

Heart 2018;104:1229-1231.

doi:10.1136/heartjnl-2018-313764

\section{REFERENCES}

1 Patel NJ, Atti V, Mitrani RD, et al. Global rising trends of atrial fibrillation: a major public health concern. Heart heartjnl-2018-313350.

2 Tikhonoff V, Kuznetsova T, Thijs L, et al. Ambulatory blood pressure and long-term risk for atrial fibrillation. Heart 2018;104:1263-70. Published Online First: 15 June 2018. doi: 10.1136/ 
3 Wachtell K. Atrial fibrillation is target organ damage caused by an impaired haemodynamic state. Heart 2018;104:1234-5.

4 van Doorn S, Geersing GJ, Kievit RF, et al. Opportunistic screening for heart failure with natriuretic peptides in patients with atrial fibrillation: a meta-analysis of individual participant data of four screening studies. Heart 2018;104:1271-5.
5 Bettencourt P, Lourenço P. Atrial fibrillation, a difficulty in the heart failure screening with natriuretic peptides. Heart 2018;104:1236-7.

6 Benziger CP, Zavala-Loayza JA, Bernabe-Ortiz A, et al. CRONICAS Cohort Study group. Low prevalence of ideal cardiovascular health in Peru. Heart 2018; 104:1251-6.

7 Brant LCC, Ribeiro ALP. Cardiovascular health: a global primordial need. Heart 2018;104:1232-3.
8 Chousou PA, Pugh PJ. How to deliver optimal cardiac resynchronisation therapy. Heart 2018;104:1300-7.

9 Shojaeifard M, Pouraliakbar HR, Houshmand G.

Asymptomatic young man with an incidental murmur. Heart 2018;104:1270.

10 Boriani G, Proietti M. Atrial fibrillation prevention: an appraisal of current evidence. Heart 2018;104:882-7. 